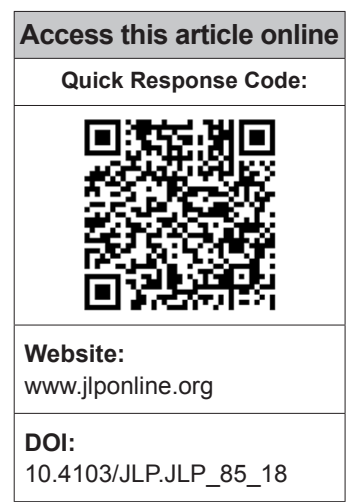

Division of Trauma Surgery and Critical Care, JPNATC, AIIMS, ${ }^{1}$ Department of Laboratory Medicine, JPNATC,

AlIMS, ${ }^{2}$ Department of Orthopaedics, AIIMS, New Delhi, India

Address for correspondence: Dr. Purva Mathur, Department of Laboratory Medicine, JPNATC, AIIMS,

New Delhi - 110029 ,

India.

E-mail: purvamathur@

yahoo.co.in

Submission: 25-06-2018

Accepted: 31-08-2018

\title{
Clinico-microbiological profile of healthcare associated pneumonia in critically ill patients at level-I trauma centre of India
}

\author{
Minu Kumari, Neha Rastogi ${ }^{1}$, Rajesh Malhotra², Purva Mathur
}

Abstract:

INTRODUCTION: Device-associated infections constitute the majority of health-care infections in Intensive Care Units (ICUs). Trauma patients are more prone to acquire such infections; ventilator-associated pneumonia (VAP) being the most common Health care associated infections (HAI) in ICU has serious implications such as increased morbidity, prolonged hospital stay, and mortality. This study aims to compare the clinicomicrobiological profile of VAP and non-VAP trauma patients at Level I trauma center.

MATERIALS AND METHODS: A 4-year retrospective study of prospectively maintained database was conducted at Level 1 trauma center from January 2013 to December 2016. The patients were classified into two groups named VAP and non-VAP patients. VAP patients were defined according to the criteria of the Centers for Disease Control and Prevention. The data were compiled and analyzed. Statistical data were analyzed using SPSS version 21 software.

RESULTS: During the study period, 134 (13\%) cases of VAP and 909 (87\%) non-VAP cases were observed in our study. The total number of ventilator days for VAP patients was 5128 days, which ranged from 2 to 82 days (median 42 days). The length of hospital stay in non-VAP category ranged from 1 to 390 days (median 195.5 days). Inhospital mortality was observed in 62 (46\%) patients with VAP. Three hundred and eighteen (35\%) non-VAP patients had also had a fatal outcome. Gram-negative organisms, most commonly Acinetobacter spp. (13, 21\%), were reported in the fatal VAP patients.

CONCLUSION AND DISCUSSION: Higher rate of mortality was observed in patients with VAP in comparison to non-VAP patients, both being on mechanical ventilation. Early recognition of VAP, implementation of proper VAP preventive bundle strategies, and stringent infection control practices are essential mandates to prevent VAP.

Key words:

Antimicrobial, infection, mortality, resistance

\section{Introduction}

T Tealth-care-associated infections (HAIs) Lhave become a global patient safety concern. ${ }^{[1]}$ Ventilator-associated pneumonia (VAP) is a type of device-associated infections, and it has a tremendous implications in terms of associated morbidity, mortality, increased

This is an open access journal, and articles are distributed under the terms of the Creative Commons Attribution-NonCommercial-ShareAlike 4.0 License, which allows others to remix, tweak, and build upon the work non-commercially, as long as appropriate credit is given and the new creations are licensed under the identical terms.

For reprints contact: reprints@medknow.com hospital stay and cost of treatment, and finally, the adverse outcome of patients. ${ }^{[2]}$

VAPisanimportantform of hospital-acquired pneumonia and specifically refers to pneumonia developed in patients on mechanical ventilator for $>48 \mathrm{~h}$ after tracheal intubation or tracheostomy. ${ }^{[3]}$ The etiology of VAP depends on multiple factors such as time of ventilation, prior administration of antibiotics, and the presence of chronic

\footnotetext{
How to cite this article: Kumari $M$, Rastogi $N$, Malhotra R, Mathur P. Clinico-microbiological profile of healthcare associated pneumonia in critically ill patients at level-I trauma centre of India. J Lab Physicians 2018;10:406-9.
} 
obstructive pulmonary disease, coma, and local factors. ${ }^{[4]}$ The prevalence of multidrug-resistant (MDR) organisms as a cause of VAP is also becoming a major health concern. Gram-negative bacteria such as Pseudomonas aeruginosa, Escherichia coli, Klebsiella pneumoniae, Acinetobacter spp., and Gram-positive bacteria such as Staphylococcus aureus are the common causative pathogens of VAP ${ }^{[5,6]}$ Delay in starting appropriate antibiotic therapy can increase the mortality associated with VAP, and thus, therapy should be started immediately. Diagnosis of VAP is difficult, which may account for over- or under-estimation of its burden. The present study was conducted to assess the clinicomicrobiological profile of VAP and non-VAP patients, their hospital stay, and subsequent outcome in our hospital setting at Level I trauma center.

\section{Materials and Methods}

The present study was conducted at the JPN Apex Trauma Center, a 165-bedded Level I trauma center of India. Patients from all over India are referred to our hospital. It is a retrospective study of laboratory-maintained database of 4 years. All the patients who were admitted to the Intensive Care Units (ICUs) for $>48 \mathrm{~h}$ and those who were on ventilator were included in the study. Patients who died or developed pneumonia within $48 \mathrm{~h}$ or those who were admitted with pneumonia at the time of admission and patients of acute respiratory distress syndrome were excluded from the study.

VAP was defined, based on the Centers for Disease Control and Prevention (CDC)'s National Healthcare Safety Network (NHSN) definitions. ${ }^{[7,8]}$ Data were collected daily, prospectively from each patient admitted to the ICU on specifically designed forms. Hospital infection control nurses are fully dedicated to this work. All the forms were validated by the clinicians and microbiologists at the end of the month to ensure that the CDC-NHSN criteria for defining HAIs were met.

A total number of 1043 patients on ventilator were studied over a period of 4 years from January 2013 to December 2016. Patients fulfilling the CDC's diagnostic criteria of VAP were included in the study. Patients with only culture positive respiratory specimens were considered as non-VAP.

Data were collected prospectively and analyzed according to age, gender, trauma type, culture positivity, hospital length of stay, number of ICU days, number of days on ventilator, and the final clinical outcome.

\section{Statistics}

Statistical analysis was performed using SPSS version 21 software (IBM, United States). All the values were expressed as mean. $P<0.05$ was considered to be statistically significant.

\section{Results}

During the above-mentioned time duration, 134 (13\%) cases of VAP and 909 (87\%) non-VAP cases were observed in our study. The incidence of VAP was more common in males, 117 (87\%) than in females, 17 (13\%). The median age of patients who developed VAP was 45 years ranging from 3 to 87 years. The different types of trauma cases who developed VAP patients were patients having neurotrauma $(30,22 \%)$, spinal trauma $(17,13 \%)$, abdominal trauma $(9,7 \%)$, thoracic trauma $(7,5 \%)$, pelvic trauma $(3,2 \%)$, and those having polytrauma $(68,51 \%)$. From the patients diagnosed to have VAP, there were a total of 505 bronchoalveolar lavage (BAL) samples and 396 blood samples received in the microbiology laboratory of our center for culture. Out of all the BAL samples, positive culture was reported in $275(54.5 \%)$, followed by $>3$ types $(167,33 \%)$ and sterile $(63,12.5 \%)$. Similarly, in the case of blood sample received in the laboratory, positive blood culture was reported in $122(31 \%)$, followed by $>3$ types $(68,17 \%)$ and sterile $(206,52 \%)$.

Isolated BAL culture was positive in 57 (43\%) VAP patients and 275 organisms were isolated from the repetitive samples of patients. Isolated blood culture was positive in $24(18 \%)$ VAP patients, and 122 clinical isolates were recovered from the repetitive samples of patients. Simultaneous BAL and blood culture positive together were observed in $16(12 \%)$ VAP patients. The total number of ventilator days for patients who had VAP were 5128 days, which ranged from 2 to 82 days (median 42 days). The lengths of hospital stay in patients who had VAP ranged from 4 to 259 days (median 131.5 days). The lengths of ICU days in these patients ranged from 3 to 93 days (median 48 days). The description of organism isolated from both VAP and non-VAP patients is shown in Table 1.

The median age of non-VAP patients was 48.5 years ranging from 1 to 96 years. There were a total of $781(86 \%)$ males and $128(14 \%)$ females in the non-VAP category. The length of hospital stay in non-VAP category ranged from 1 to 390 days (median 195.5 days).

\section{Clinical outcome}

A total of $72(54 \%)$ patients were discharged and $62(46 \%)$ patients who developed VAP had a fatal outcome. Three hundred and eighteen (35\%) non-VAP patients had also had a fatal outcome. A high rate of antimicrobial resistance was observed in this study, and most of the isolates were sensitive only to colistin and tigecycline. Out of the total 134 VAP patients, Acinetobacter spp. $(60 \%)$ was the most common isolate 
Table 1: Organisms isolated from both ventilator-associated pneumonia and nonventilator-associated pneumonia patients

\begin{tabular}{llcc}
\hline & Organisms & $\begin{array}{c}\text { Non-VAP } \\
\text { patients (\%) }\end{array}$ & $\begin{array}{c}\text { VAP patients } \\
(\%)\end{array}$ \\
\hline $\begin{array}{l}\text { Gram-positive } \\
\text { organism }\end{array}$ & $\begin{array}{l}\text { Staphylococcus } \\
\text { aureus }\end{array}$ & $10(3)$ & $79(4.6)$ \\
Enterococcus spp. & 0 & $2(0.1)$ \\
Gram-negative & Acinetobacter spp. & $164(60)$ & $1009(58.2)$ \\
organism & $\begin{array}{l}\text { Pseudomonas spp. } \\
\text { Enterobacteriaceae }\end{array}$ & $46(17)$ & $238(13.7)$ \\
& $\begin{array}{l}\text { Burkholderia spp. } \\
\text { Stenotrophomonas }\end{array}$ & $7(3)$ & $319(18.4)$ \\
& spp. & & $40(2.3)$ \\
& $\begin{array}{l}\text { Chryseobacterium } \\
\text { spp. }\end{array}$ & $3(1)$ & $6(1.3)$ \\
& Elizabethkingia spp. & 0 & $9(0.5)$ \\
& Sphingomonas spp. & 0 & $9(0.5)$ \\
\hline
\end{tabular}

VAP $=$ Ventilator-associated pneumonia

in BAL sample and Enterobacteriaceae (36\%) in blood sample. Gram-negative organisms, most commonly Acinetobacter spp. $(13,21 \%)$, were reported in the fatal VAP patients.

\section{Discussion}

VAP is an important hospital-acquired infection (HAI) among patients in ICU receiving mechanical ventilation. It is the second most common HAI in the ICU and the most common HAI in the patients on ventilator support. ${ }^{[9,10]}$ VAP has grave consequences, especially in critically ill trauma victims due to multiple attributes such as increased and prolonged use of invasive mechanical ventilation and inadvertent use of antibiotic therapy eventually leading to poor clinical outcome and progressively increasing antimicrobial resistance. Despite major advances in techniques for the management of VAP and the routine use of effective procedures to disinfect respiratory equipment, VAP continues to complicate the course of $8 \%-28 \%$ of the patients receiving mechanical ventilation. ${ }^{[11]}$ It is a condition difficult to diagnose accurately and too expensive to treat. Its development prolongs the patient's ICU stay and is associated with high rate of morbidity and mortality ${ }^{[12]} \mathrm{A}$ favorable outcome seems to be more likely if appropriate antibiotics are prescribed timely.

The incidence of VAP in our study was only $13 \%$, while it is reported to be $28 \%, 37 \%$, and $38.5 \%$ in some of the studies. ${ }^{[13-15]}$ We have a very stringent, bundle-based preventive program with continuous surveillance, which may be a reason for the lower rates. ${ }^{[6,16]}$ In our study group, most of the patients consisted of middle-aged population and mostly consisted of males $(117,87 \%)$ and females $(17,13 \%)$ in VAP patients; the same result has been published in numerous studies. ${ }^{[17,18]}$
Inourstudy, wereported thatmost of the pathogens causing VAP were Gram-negative bacteria such as Acinetobacter baumannii $(60 \%)$ and Enterobacteriaceae $(36 \%)$, similar to what has been reported in some other studies. ${ }^{[19]}$ The clinical isolates responsible for VAP vary according to the duration of mechanical ventilation, antibiotic dose, ventilator days, and duration of ICU stay. Patients on airway intubation are associated with increased number of Gram-negative bacterial colonization of the upper and lower respiratory tract with subsequent overgrowth and pneumonia.

Numerous studies have shown that MDR bacteria are becoming increasingly prevalent in the hospital environment as a result of the extensive use of antibiotics. ${ }^{[20-22]}$ In VAP cases, the usage of antibiotics before the diagnosis of VAP was significantly higher as compared with the non-VAPs, and justification for this lies in the fact that the patients were critically ill necessitating empiric therapy before the results of culture and sensitivity are known. Most of the organisms in our study were MDR being sensitive only to colistin and tigecycline in most of the cases. These findings suggest that the most important strategies for controlling the problem of MDR organisms in the ICU should be directed toward continuously monitoring the presence of these organisms and the avoidance of excessive or continued use of any single drug over a long period.

\section{Conclusion}

VAP patients have higher mortality rate, longer duration of ICU stay, and ventilator days in comparison to non-VAP patients. Appropriate antibiotic treatment on immediate identification of VAP patients, proper hand hygiene, and other healthy habits can prevent the cases of subsequently occurring VAP cases in every hospital settings. Knowledge of sensitivity pattern of pathogens should guide the choice of antibiotics as there is an increasing evidence of MDR pathogens in patients who develop VAP. Regular fumigation of ICUs and sterilization of ventilators will decrease the incidence of VAP cases.

\section{Financial support and sponsorship}

Nil.

\section{Conflicts of interest}

There are no conflicts of interest.

\section{References}

1. Safety WP. World Health Organization, WHO guidelines on hand hygiene in health care. 2009. Available from: http:/ / whqlibdoc. who. int/publications/2009/9789241597906_eng. pdf. [Last accessed on 2018 Jun 10].

2. Kanj S, Kanafani Z, Sidani N, Alamuddin L, Zahreddine N, 
Rosenthal V. International nosocomial infection control consortium findings of device-associated infections rate in an Intensive Care Unit of a Lebanese university hospital. J Glob Infect Dis 2012;4:15-21.

3. McFee RB. Nosocomial or hospital-acquired infections: An overview. Dis Mon 2009;55:422-38.

4. Rello J, Sa-Borges M, Correa H, Leal SR, Baraibar J. Variations in etiology of ventilator-associated pneumonia across four treatment sites: implications for antimicrobial prescribing practices. American journal of respiratory and critical care medicine. 1999;160:608-13.

5. Available from: https://www.cdc.gov/nhsn/ps-analysisresources/reference-guides.html. [Last accessed on 2018 May 20].

6. Batra P, Mathur P, John NV, Nair SA, Aggarwal R, Soni KD, et al. Impact of multifaceted preventive measures on ventilatorassociated pneumonia at a single surgical centre. Intensive care medicine 2015;41:2231.

7. Hunter JD. Ventilator associated pneumonia. BMJ 2012;344:e3325.

8. Afshari A, Pagani L, Harbarth S. Year in review 2011: Critical care - infection. Crit Care 2012;16:242-7.

9. NNIS System. National nosocomial infections surveillance (NNIS) system report, data summary from January 1990-May 1999, issued June 1999. A report from the NNIS system. Am J Infect Control 1999;27:520-32.

10. Rakshit P, Nagar VS, Deshpande AK. Incidence, clinical outcome and risk stratification of ventilator-associated pneumonia - A prospective cohort study. Indian J Crit Care Med 2005;9:211-6.

11. Gadani H, Vyas A, Kar AK. A study of ventilator-associated pneumonia: Incidence, outcome, risk factors and measures to be taken for prevention. Indian J Anaesth 2010;54:535-40.

12. Saldanha Dominic RM, Prashanth HV, Shenoy S, Baliga S. A clinico-microbiological study of ventilator-associated pneumonia in a tertiary care hospital. Int J Biol Med Res 2012;3:1651-4.

13. Gupta A, Agrawal A, Mehrotra S, Singh A, Malik S, Khanna A, et al. Incidence, risk stratification, antibiogram of pathogens isolated and clinical outcome of ventilator associated pneumonia. Indian J Crit Care Med 2011;15:96-101.

14. Koenig SM, Truwit JD. Ventilator-associated pneumonia: Diagnosis, treatment, and prevention. Clin Microbiol Rev 2006;19:637-57.

15. Ranjan N, Chaudhary U, Chaudhry D, Ranjan KP. Ventilator-associated pneumonia in a tertiary care Intensive Care Unit: Analysis of incidence, risk factors and mortality. Indian J Crit Care Med 2014;18:200-4.

16. Mathur P, Tak V, Gunjiyal J, Nair SA, Lalwani S, Kumar S, et al. Device-associated infections at a level-1 trauma centre of a developing nation: Impact of automated surveillance, training and feedbacks. Indian J Med Microbiol 2015;33:51-62.

17. Dey A, Bairy I. Incidence of multidrug-resistant organisms causing ventilator-associated pneumonia in a tertiary care hospital: A nine months' prospective study. Ann Thorac Med 2007;2:52-7.

18. Rasslan O, Seliem ZS, Ghazi IA, El Sabour MA, El Kholy AA, Sadeq FM, et al. Device-associated infection rates in adult and pediatric Intensive Care Units of hospitals in Egypt. International Nosocomial Infection Control Consortium (INICC) findings. J Infect Public Health 2012;5:394-402.

19. Fathy A, Abdelhafeez R, El-Gilany A, AbdElhafez SA. Analysis of ventilator associated pneumonia (VAP) studies in Egyptian University Hospitals. Egypt J Chest Dis Tuberc 2013;62:17-25.

20. Stanek F, Findeis H, Gebhardt G. A classification apparatus for the classification of direct-current output voltages of the precision noise-impulse-level meters type 00017 and 00023. Z Gesamte Hyg 1979;25:186-7.

21. Khattab AA, El-Lahony DM, Fathy W. Ventilator associated pneumonia in a neonatal Intensive Care Unit. J Am Sci 2013;9:251-8.

22. Bonten MJ, Kollef MH, Hall JB. Risk factors for ventilator-associated pneumonia: From epidemiology to patient management. Clin Infect Dis 2004;38:1141-9. 